\title{
Total Prostatectomy in a Dog with Perineal Hernia
}

\author{
M. İrem BAŞER ${ }^{1}$, Yusuf ŞEN ${ }^{1}$, Şevket ÖZVEREL ${ }^{*}$, Erfaneh PİRPANAHİ ${ }^{1}$, Ozan AHLAT $^{1}$, \\ Fati QOTI'1 1 Ali BUMİN ${ }^{1}$, Osman KUTSAL ${ }^{2}$
}

\author{
${ }^{1}$ Ankara University, Veterinary Faculty, Surgey Department, 06110, Ankara, Turkey \\ 2Ankara University, Veterinary Faculty, Pathology Department, 06110, Ankara, Turkey,
}

\begin{abstract}
When perineal muscles separates, one or many organs of the pelvic and abdominal cavity displaces beneath skin and form swelling in different sizes, stiffnesses and forms. This is called perineal hernia. 10 years old, unneutered male Rottweiller dog operated because of swelling in the perineal area. In the operation, 9-10 cm structure of vasculated mass had been detected. Structure diagnosed as a prostate gland. Suspicion of malign enlargement leaded to total prostatectomy and after anastomosis of cranial and caudal side of urethra. Area closed (sutured) in appropriate techniques. Patient became healthy without complication postoperatively. Histopathologic examination reveals subacute prostatitis with papillary hyperplasia of prostate and adenocarcinomatous lesions.
\end{abstract}

Keywords: Prostatectomy, Perineal Hernia, Dog.

\author{
$* * *$ \\ Perineal Hernialı Bir Köpekte Total Prostatektomi Olgusu
}

ÖZ

Perineal kasların ayrılması sonucunda pelvik ve abdominal boşluk organlarının bir veya birkaçının perineal bölgede deri altına yer değiştirmesi sonucu bu bölgede değişik büyüklükte, kıvamda ve şekilde şişkinlik oluşturmasına perineal fittk denir. 10 yaşında, Rottweiller 1 rkı ve kısırlaştırılmamış erkek bir köpek, perineal bölgede gelişen şişkinlikten dolayı operasyona alındı. Operasyonda 9-10 cm boyutunda ve üzeri damarlı kitlesel bir yap1 ile karşılaşıldı. İncelemede yapının prostat olduğu anlaşıldı. Kötü huylu bir büyüme olabileceği şüphesi üzerine total prostatektomi ve sonrasında üretranın kranial ve kaudal uçlarının anastomozu yapıldı. Bölge daha sonra tekniğine uygun olarak kapatıldı. Hastanın postoperatif olarak komplikasyonsuz iyileştiği görüldü. Histopatolojik inceleme sonucunda; papiller kistik prostat hiperplazisi ve adenokarsinomatöz odaklara sahip subakut prostatitis tanısı konuldu.

Anahtar Kelimeler: Perineal Hernia, Prostatektomi, Köpek.

To cite this article: Başer M.I. Şen Y. Özverel S. Pirpanahi E. Ablat O. Qqti F. Bumin A. Kutsal O. Total Prostatectomy in a Dog with Perineal Hernia. Kocatepe Vet J. (2021) 14(1):159-165

Submission: 22.09.2020 Accepted: 15.12.2020 Published Online: 26.02.2020

ORCID ID; MIB: 0000-0002-3784-9820, YŞ: 0000-0002-8137-3858, ŞÖ: 0000-0002-5997-1608, EP: 0000-0003-0427-6517,

OA: 0000-0002-2580-8140, FQ: 0000-0001-5751-0675, AB: 0000-0001-8468-1330, OK: 0000-0003-3599-6867

*Corresponding author e-mail: sevket.ozverel@hotmail.com 


\section{GİRİş}

Perineal bölgeyi oluşturan kasların değişik nedenlerden dolayı ayrilması sonucu pelvik ve abdominal boşlukta bulunan organların bir veya birkaçının perineal bölgede deri altına toplanarak farklı büyüklük, şekil ve kıvamda şişkinlik oluşturmasina perineal fitık denir. Fitık kesesi içerisinde pelvik veya retroperitonal yağ dokusu, seroz s1v1, deviye olmuş ya da dilate rektum, rektal divertikulum, prostat, idrar kesesi veya ince bağırsaklar bulunabilir (Head ve Francis 2002, Bennett 2018).

Perineal kas diyaframının zayıflaması ve intrapelvik bağ dokusu yapılarının esnemesi sonucunda bozulan anatomik yap1 kaudal abdominal organlarin (idrar kesesi, prostat) herniasyonuna, rektumun deviasyonuna ve divertikülüne yol açar (Bellenger ve Canfield 2003). Perineal hernia çoğunlukla yaşlı kısırlaştırılmamış erkek köpeklerde görülür. Hormonal etkiler, perineal kas sisteminin üzerinde zayıflatıcı etkiye sahiptir. Neden olan diğer faktörler arasında rektal hastalık, prostatomegali ve perineal diyaframın anatomik bozukluğu yer almaktadır. Perineal herniasyon hemen hemen sadece yaşli erkek köpeklerde gelişir, bu durum erkek ve dişi köpekler arasındaki olası anatomik ve hormonal etki farkını gösterir (Head ve Francis 2002).

Perineal bölgedeki şişlik unilateral ya da bilateral olabilir. Bu bölgedeki anal bezlerin hastalıkları ya da tümörleri ile karışabilir. Hastalığın kesin tanısı ve bölgenin diğer hastalıklarından ayırıcı tanısı için klinik, radyografik ve ultrasonografik muayene yapilmalıdır. Tanı konulduktan sonra sağaltımı cerrahi olarak yapilmalıdır (Head ve Francis 2002, Fossum 2013).

$\mathrm{Bu}$ olguda, perineal hernialı bir köpekte ilk kez prostatın fitıklaşması ile karşılaştık. Bunun sağaltımı ve sonuçlarını meslektaşlarımız ile paylaşmayı amaçladik.

\section{Olgu Tanımı}

İncelediğimiz olgu 10 yaşında, Rottweiller 1rk1, kısırlaştırılmamış bir erkek köpektir. Olgu Ankara Üniversitesi Veteriner Fakültesi Cerrahi Kliniği'ne, Ankara dışında özel bir klinikten acil olarak sevk edilmiş olarak geldi. Hasta sahibinden alınan anamnezde, iki hafta öncesinde perineal bölgede yavaş yavaş büyüyen bir şişkinlikten dolayı köpeğini özel bir kliniğe götürdüğü ve muayenede Veteriner Hekim tarafindan soğuk apse tanısı konulduğu bilgileri alındı. Hasta sahibi anamnezinde sağaltım amacıyla lokal olarak pomad iyot iyodür başlandığ1 ve iki hafta kullandiktan sonra tekrar gelmeleri söylendiğini bildirdi.

İki hafta pomad kullanımı sonunda hastanın kliniğe tekrar götürüldüğü ve bu bölgeye Veteriner Hekim tarafindan punksiyon yapıldığ1 ancak punksiyon iğnesinden içerik gelmemesi sonucu hastanın Ksilazin hidroklorür (2 mg/kg, BASİLAZIN \%2- Ksilazin hidroklorür 23,32 mg, Bavet, Türkiye) ve Ketamin hidroklorür (10 mg/kg, Ketasol \%10- Ketamin hidroklorür $100 \mathrm{mg}$. Benzetonyum klorür 0,1 mg, Interhas, Türkiye) ile anesteziye alınıp bölgeye cerrahi girişimde bulunulduğu bilgisi alındı.

Cerrahi girişim sonrasında bölgede oldukça çok kan damarına sahip solid bir kitlenin Veteriner Hekim tarafindan görülerek kitleye herhangi bir girişimde bulunamayacağını söylemesi sonucu var olan kanamaların elektrokoter ile durdurulmaya çalışıldığ1 ve deriye basit ayrı dikiş atılarak acilen kliniğimize yönlendirildiği öğrenildi.

İnspeksiyonda, perineal bölgede anüsün sağ üst tarafina dikiş atıldığ1 ve bu bölgede sızıntı tarzında kanama olduğu tespit edildi. Palpasyonda şişliğin belirgin ve sert olmasindan dolayı köpeğin acilen operasyona alınmasına karar verildi.

Perianal bölge geniş bir şekilde tıraş edildikten sonra antisepsi işlemleri yapıldı. Rutin cerrahi hazırlıktan sonra anestezi indüksiyonu için $6 \mathrm{mg} / \mathrm{kg}$ Propofol (Propofol ${ }^{\circ} \% 1$ Fresenius İlaç San. İtalya) bolus şeklinde intravenöz olarak uygulandiktan sonra operasyon süresince \%3-3,5 konsantrasyonunda Isofluran (Isoflurane USP® Adeka İlaç San., Hollanda) \%100 oksijen ile birlikte verilerek idame anestezisi sağlandi.

Hasta operasyon masasina sternal pozisyonda yatırıld 1 ve pelvis bölgesi operasyon kolaylı̆̆ı için yukarıya kaldırıldı. Hastaya perioperatif analjezi amaciyla (morfin 0,01 mg/kg sc Morphine®) Osel İlaç San. İstanbul) ve antibiyoterapi amaciyla (sefalosporin 20 $\mathrm{mg} / \mathrm{kg}$ iv (Cefozin ${ }^{\circledR}$ Bilim İlaç San. İstanbul) ilaçlar uygulandi.

Operasyona bölgede bulunan ve daha önceki klinikte Veteriner Hekim tarafindan atılan dikişler alınarak başlandı. Bölgede bulunan dikişler uzaklaştırıldıktan sonra perineal bölgedeki kaslarin normal anatomik yapısının kaybolduğu ve bölgede yaklaşık tenis topu büyüklüğünde $9-10 \mathrm{~cm}$ boyutunda vaskülizasyonu fazla, multi-lobüler kitlesel bir yap1 olduğu görüldü (Şekil 1). Yapılan palpasyon ve inspeksiyon ile kitle incelendiğinde bu yapının prostat olduğu anlaşıldı.

Köpeğin yaşı da göz önüne alındığında kötü huylu bir büyüme olabileceği düşüncesi ile Total Prostatektomi operasyonu yapilmasina karar verildi. Bunun üzerine idrar kesesine idrar yolu kateteri yerleştirildi. Kateterinin k1lavuzluğunda prostatın kranial ve kaudalinde bulunan üretra penslerle tutulduktan sonra prostat total olarak bölgeden uzaklaştırıldı.

Prostatın tamamen uzaklaştırılmasından sonra üretranın kranial ve kaudal uçlarının uç uca anastomuzu, 4/0 PDS ile basit ayrı dikişler atılarak yapıldı (Şekil 2). İdrar kesisi üzerinde iatrojenik olarak oluşturulan 1-2 cm'lik ensizyon 4/0 PDS ile Schmieden ve Lembert dikişleri ile kapatıldı.

Daha sonra prostat ile beraber fitıklaşmış olan idrar kesesi normal anatomik yerine yerleştirildi (Şekil 3). Bölgeyi oluşturan perineal kasların rekonstrüksiyonu, anatomik konumları korunarak 0 prolen dikiş materyali ile basit ayrı ve sürekli dikişlerle sağlandı. 
Derialtı bağ doku ve deri tekniğine uygun olarak kapatıld1. Uygulanan sonda üretrada birakıldı ve Chinese Finger Trap dikişleri ile prepisyuma sabitlendi.

Perianal bölge fitıklarının nedenleri arasında sayıldığ için hastaya anestezi altındayken kastrasyon operasyonu da yapıld1. Hasta anesteziden uyandiktan sonra yakalık takılarak hasta sahibine teslim edildi.

Postoperatif antibiyoterapi için amoksisilin klavulanik asit (20 mg/kg, oral) yedi gün için reçete edildi. Bölgedeki kasların ve dikişlerin zorlanmaması için hastanın 1kınmasinı engellemek amaciyla, hastanın en az 10 gün süreyle yumuşak gidalarla beslenmesi önerildi.

Hastanın 3. 5. ve 15. gün kontrollerinde herhangi bir postoperatif komplikasyon geliştirmediği, ürinasyon ya da defekasyonda sıkıntı yaşamadığı ve operasyon bölgesinin de herhangi bir komplikasyon şekillenmeden iyileştiği tespit edildi. Hastanın akciğer radyografisi alınarak ve abdominal ultrasonografisi yapılarak metastaz açısından değerlendirme yapıldı. İdrar kesesine yerleştirilmiş olan kateter 5. günde çıkarild1.

Prostatın patolojik incelemesi için alınmış olan prostat $\% 10$ 'luk formalinde 24 saat süre ile tespit edildikten sonra doku takip cihazında (Leica TP1020) dereceli alkollerden ve ksilolden geçirilerek parafine bloklandı (Thermo Shandon Histocentre 3). Bloklardan alınan (Leica RM2255) $5 \square$ m'lik kesitler Hematoksilen ve Eozin (HE) boyası ile boyand1 (Leica Autostainer XL) ve entellan ile kapatıld1 (Leica CV5030). Hazırlanan preparatlardan kameralı 1ş1k mikroskobunda (Olympus BX51-DP71) mikrofotoğraflar çekildi.

Prostatın makroskopik muayenesinde; 80 gr ağırlı̆̆ında ve $6 \mathrm{~cm}$ çapinda olup, hafif yumuşakelastiki kıvama sahip olduğu ve kesit yüzü sarımsı-boz beyaz renkte ve multilobüler görünümde olduğu rapor edildi (Şekil 4).

Mikroskobik incelemede bezlerin lumene doğru papiller tarzda üremeler gösterdiği ve yer yer kistik görünümde oldukları dikkati çekti. Bazı mikroskop sahalarında hiperplazik bez yapılarının epitel hücre çekirdekleri hiperkromatik ve atipik görünümdeydi (Şekil 5). Ayrica bezlerin arasında ödem, çoğunlukla nötrofil lökosit, plazma hücresi ve makrofajlardan oluşan aralarında tek tük lenfositlerin de yer aldığ1 yang1sal hücre infiltrasyonları ile birlikte bağ doku artışı ve kanama alanları da fark edildi. Yang1sal hücrelere bez lumenlerinde de rastlandi.

Alınmış olan prostatın patolojik incelemesi sonucunda papiller kistik prostat hiperplazisi ve adenokarsinomatöz odaklara sahip subakut prostatitis tanisi konuldu ve total prostektomi operasyonu ile malign odaklarının ilerlemesi ve yayılımının önüne geçildiğine karar verildi.

\section{TARTIŞMA ve SONUÇ}

Perineal hernialarda bölgenin anatomik konumundan dolayı değişik organlar fitıklaşabilir. Bilbrey ve ark.
(1990) yaptıkları çalışmada idrar kesesinin ve prostatın fitıklaşmasının perineal herniaya sahip olan köpeklerin \%18'inde görüldüğünü bildirmelerine karşın, bu raporda belirtilen köpek bizim kliniğimizde karşılaşılan ve kayıtlarda bulunan prostatın perineal herniadan fitıklaştığı ilk olgudur. Çalışmalarda idrar kesesi fitıklaşması olan hayvanlarda sıklıkla perineal hernia ile görülen kabızlık ve perineal bölgedeki şişkinliğe ek olarak idrar tıkanıklığı belirtileri görülebildiği söylenmektedir ancak bizim olgumuzda operasyon öncesi perineal bölgede şişkinlik dişında hiçbir klinik belirti bulunmamaktaydı. Perineal hernia operasyonlarından sonra idrar kesesi ve prostatın tekrar fitıklaşmasının önlenmesi adına duktus deferenslerin fikzasyonu ya da idrar kesesinin abdominal duvara sabitlenmesi gibi birçok yöntem uygulanabilmektedir (Bilbrey ve ark. 1990). Bizim olgumuzda kastrasyon yapılmıs olması, prostatın total rezeksiyonu ve üretranın kısalmış olması sebebiyle herhangi bir organın fikzasyonuna ihtiyaç duyulmamıs ve nüks görülmemiştir.

Prostat neoplazisi köpeklerde nadir olarak görülür ve en s1k görülen histolojik tümör tipi adenokarsinomdur. Daha az yaygin olan epitelyal menşeli tipler arasında skuamöz hücreli karsinom, değişken hücreli karsinom ve farklılaşmamış karsinom bulunmaktadir. Leiomyom, leiomyosarkom ve hemanjiyosarkom gibi mezenkimal tümörler nadirdir. Köpeklerde prostatı etkileyen tümörler arasında ayrıca lenfoma da bildirilmiştir (Watanabe ve ark. 2018, Lawrence 2012). Köpeklerde prostat hastalıkları özellikle 5 yaş ve üzeri, Alman Çoban ve Rottweiller gibi büyük 1rklarda görülmektedir (Fossum 2013, Bellenger ve Canfield 2003). Bu çalışmalara bakıldığında bizim olgumuzun Rottweiller 1 rk1 ve 5 yaş üstünde bir köpekte görülmesi ayrıca patolojik tanının adenokarsinom olması diğer çalışmalarla uyumludur.

Total prostatektomi, metastaz yapmamış tümörleri olan hastalar için kullanılabilir; ancak diğer sağaltımlara yanıt vermeyen şiddetli travma veya kronik prostat hastalığı için nadiren uygulanır. Operasyon sonrası hastada üriner inkontinans s1k görülür ve tanı anında prostatik tümörlerin metastaz yapmış olma oranları çok yüksek olduğunda da bu prosedür nadiren yapilır (Fossum 2013, Cornell ve ark. 2000). Bizim olgumuzda operasyona girerken prostatektomi yapma planı olmasa dahi prostatın patolojik incelemesi sonucu adenokarsinom görüldüğü için total olarak alınmasının hastanın operasyon sonrası yaşam kalım süresini uzattığ1 görülmektedir. Ayrıca yapılan çalışmalarda üriner inkontinans, tüm olguların \%33 ile \%100'ünde bildirildiği gibi total prostatektomi sonrası en sik görülen komplikasyondur (Freitag ve ark. 2007, Goldsmid ve Bellenger 1991). Ancak bizim olgumuzda operasyon sonrası inkontinansa rastlanılmamıştır bu durum Goldsmid ve Bellenger (1991) çalışması ile uyumlu görülmektedir. Goldsmid ve Bellenger (1991) prostatik hastalığ1 olan 11 köpekte 
total prostatektomilerden sonra \%33'lük bir inkontinans oranı rapor ettiklerini bildirdiler. Bu durum, diğer çalışmalarla karşılaştırıldığında daha düşük inkontinans oranının, prostat duvarına yakın dikkatli diseksiyondan, önemli nörovasküler yapıların zarar görmesinden kaçınılmasından ve prostatın hem kranial hem de kaudal uçlarının mümkün olduğunca az eksize edilerek daha fazla prostatik idrar yolunun korunmasina özen gösterilmesinden kaynaklanmış olabilir (Goldsmid ve Bellenger 1991). Yazarlar ayrıca preoperatif inkontinans ile prostatik neoplazi ve postoperatif inkontinans arasında bir ilişki olabileceğini bildirdiler. Çalışmada postoperatif idrar inkontinansı görülen üç köpekten birinde başvuru şikayeti olarak idrar inkontinans1, diğerinde prostatik neoplazi, bir diğer köpekte ise prostatik neoplazi ve preoperatif idrar inkontinansı şikayeti olduğu rapor edildi. Çalışmada diğer köpeklerin çoğu prostatitis için total prostatektomi geçirdi (Goldsmid ve Bellenger 1991). İlginç bir şekilde, prostatik hastalığ1 olmayan köpeklerde total prostatektomiyi değerlendiren bir çalışmada, 10 köpeğin hiçbirinin postoperatif dönemde inkontinans yaşamadığı bildirildi ve bu durum inkontinansin cerrahi ile kombine olan altta yatan prostatik hastalık ile ilişkili olabileceğini düşündürmektedir (Vnuk ve ark. 2008, White 2000).
$\mathrm{Bu}$ yüksek komplikasyon oranı nedeniyle, total prostatektomi genellikle önerilmemektedir. Ancak, prostatektomi prostatik neoplazili köpekler için daha uygun bir seçenek haline gelebilir, çünkü sağaltım daha kesindir ve erken tanı ile cerrahiye daha yatkın küçük lezyonlar yakalanabilir (Freitag 2007). Total prostatektomi, yardımcı sağaltımlar ile kombine edildiğinde, prostat karsinomlu köpeklerin önceki raporlarına göre yaşam süresini uzatır ve komplikasyon oranlarını azaltır. Bununla birlikte, olgu seçiminin postoperatif sonuçta önemli bir rol oynadığ1 belirtilmektedir (Bennett 2018).

Olgumuzdaki gibi acil ameliyata ihtiyaç duyulmayan olgularda, mutlaka operasyon öncesi fitık bölgesinin ultrasonografik değerlendirilmesinin yapılması operasyon planlamasını yapabilmek açısından önemlidir. Tümör görülen olgularda, tümörden biyopsi örneğinin alınması, yine preoperatif akciğer radyografilerinin alınması ve kan analizlerinin yapılması, metastaz değerlendirmesinde ve olguya yaklaşım stratejisinin belirlenmesinde büyük önem taşıdı̆̆1nı düşünmekteyiz.

$\mathrm{Bu}$ olgu sunumunda kliniklerimizde siklikla karşılaşılan perineal hernia hastası köpekler arasında kliniğimizde ilk defa prostatın fitıklaşmış olduğu bir olgu ile karşılaştık. Bu olgunun sağaltımını ve sonuçlarını meslektaşlarımız ile paylaşmayı amaçladık.

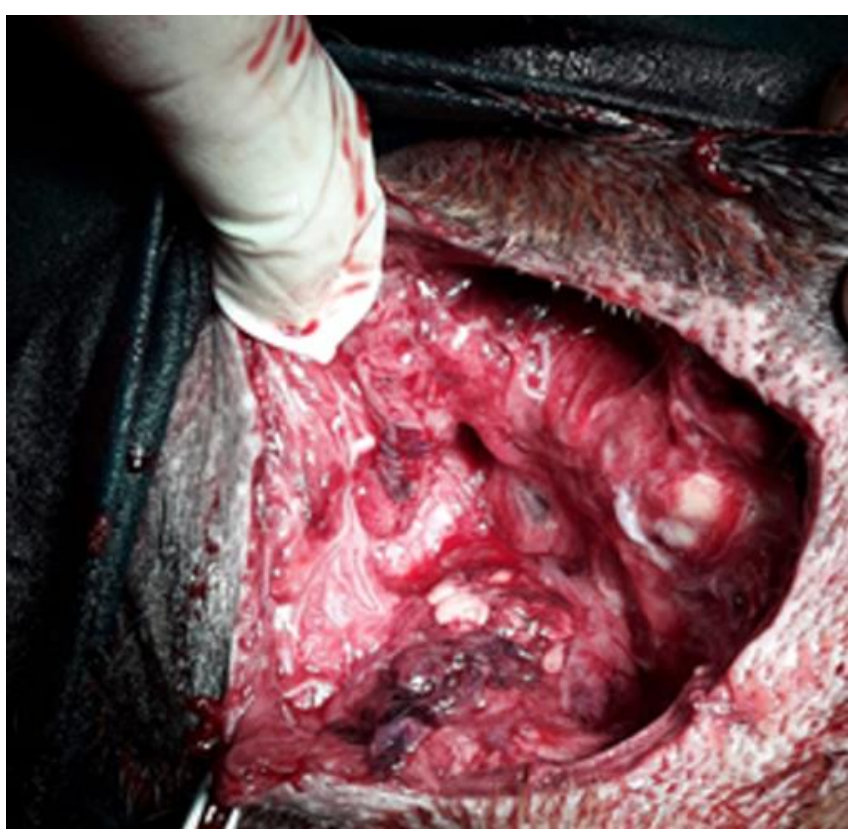

Şekil 1: Bölge açıldığında karşılaşılan prostatın fitıklaştığının görüldüğü fotoğraf.

Figure 1: Image that shows herniated prostate after incision of the area. 


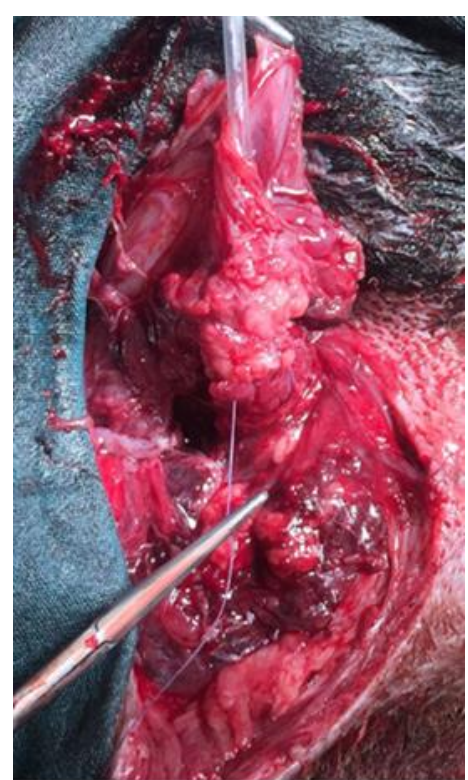

Şekil 2: Üretral anastomoz yapılırken; üretradan geçirilen ve idrar kesesinden çıkarılan kateter görülmekte. Figure 2: During urethral anastomosis; catheter shown that passes from urethra and exits from urinary bladder.

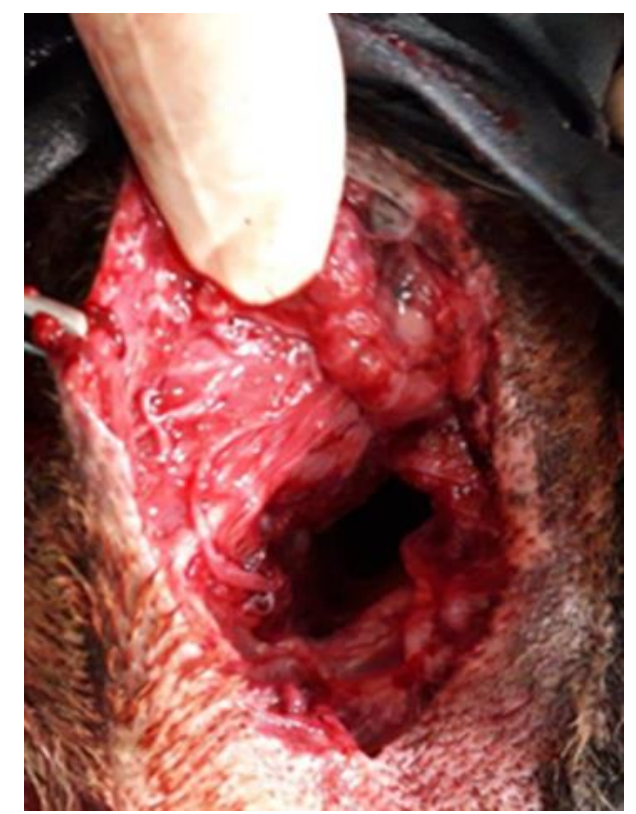

Şekil 3: Total prostatektomiden sonra bölgede bulunan perineal açıklı̆̆ın görüntüsü.

Figure 3: Perineal space image after total prostatectomy. 


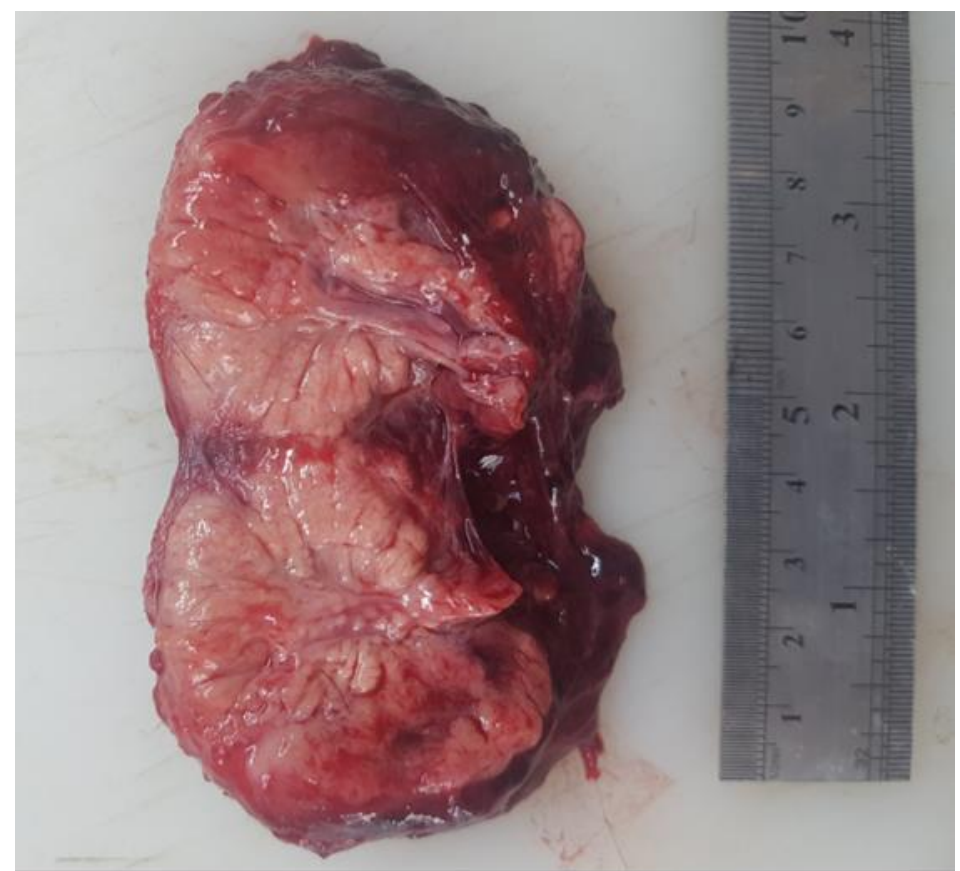

Şekil 4: Alınan prostatın makroskobik görüntüsü.

Figure 4: Macroscopic image of extirpated prostate.

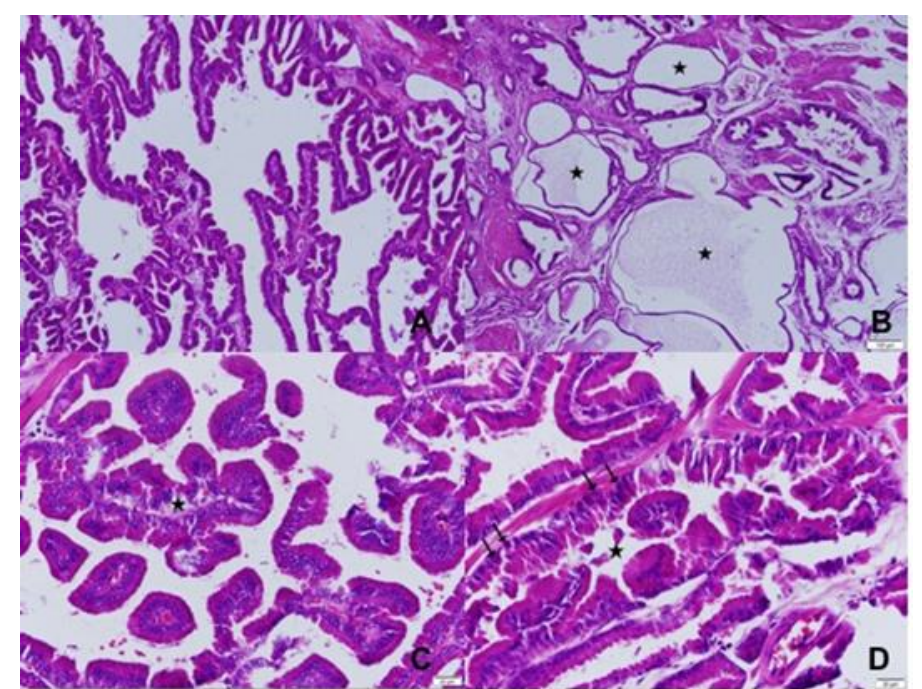

Şekil 5 A: Prostat bezinde papiller hiperplazi, HE. B. Prostat bezinde papiller hiperplazi (yıldız), HE. C. Kistik prostat bezleri (ylldılar), HE. D. Prostat bezinde adenokarsinomatöz odak (yıldız), hiperkromatik ve atipik görünümdeki hücreler (oklar), HE.

Image 5 A: Papillary hyperplasia of prostate gland, HE. B. Papillary hyperplasia of prostate gland (star), HE. C. Cystic prostate glands (stars), HE. D. Adenocarcinomatous focal area (star), hyperchromatic and atypical cells (arrows) of prostate gland HE. 
Çıkar çatışması: Yazarlar bu yazı için gerçek, potansiyel veya algılanan çıkar çatışması olmadığını beyan etmişlerdir.

Etik izin: Bu çalışma "Hayvan Deneyleri Etik Kurullarının Çalışma Usul ve Esaslarına Dair Yönetmelik" Madde 8 (k) gereği HADYEK iznine tabi değildir.

\section{KAYNAKLAR}

Agnew DW, MacLachlan NJ. Tumors of the Genital Systems, In: Tumors in Domestic Animals, Ed; Meuten DJ, 5th Ed., John Wiley \& Sons, Inc., Ames, Iowa, USA. 2017; pp. 714-717.

Bellenger CR, Canfield RB. Perineal Hernia, In: Textbook of small animal surgery, Ed; Slatter DH, 3rd Ed., Elsevier health sciences, USA. 2003; pp. 487-497.

Bennett TC, Matz BM, Henderson RA, Straw RC, Liptak JM, Selmic LE, Collivignarelli F, Buracco P. Total prostatectomy as a treatment for prostatic carcinoma in 25 dogs. Vet Surg. 2018; 47(3):367-377.

Bilbrey SA, Smeak DD, DeHoff W. Fixation of the deferent ducts for retrodisplacement of the urinary bladder and prostate in canine perineal hernia. Vet Surg. 1990; 19(1):24-7.

Cornell KK, Bostwick DG, Cooley DM, Hall G, Harvey HJ, Hendrick MJ, Pauli BU, Render JA, Stoica G, Sweet DC, Waters DJ. Clinical and pathologic aspects of spontaneous canine prostate carcinoma: a retrospective analysis of 76 cases. Prostate. 2000; 45(2):173-83.

Freitag T, Jerram RM, Walker AM, Warman CGA. Surgical management of common canine prostatic conditions. Compend Contin Educ Vet. 2007; 29(11):656-672.

Goldsmid SE, Bellenger CR. Urinary incontinence after prostatectomy in dogs. Vet Surg. 1991; 20(4):253-6.

Head LL, Francis DA. Mineralized paraprostatic cyst as a potential contributing factor in the development of perineal hernias in a dog. J Am Vet Med Assoc. 2002; 221(4):533-535.

Johnston SD, Kamolpatana K, Root-Kustritz MV, Johnston GR. Prostatic disorders in the dog. Anim Reprod Sci. 2000; 60-61:405-15.

Lawrence JA, Saba CF. Tumors of the male reproductive system, In: Withrow and MacEwen's Small Animal Clinical Oncology, Ed; Withrow SJ, Vail DM, Page RL, $5^{\text {th }}$ Ed., Elsevier Inc., USA. 2012; pp. 557-571.

Polisca A, Troisi A, Fontaine E, Menchetti L, Fontbonne A. A retrospective study of canine prostatic diseases from 2002 to 2009 at the Alfort Veterinary College in France. Theriogenology. 2016; 85(5):835-840.
Radlinsky MG. Chapter 20: Surgery of the Digestive System, In: Small Animal SURGERY, Ed; Fossum TW, Dewey CW, Horn CV, Johnson AL, MacPhail CM, Radlinsky MG, Schuls KS, Willard MD, 4th Ed., Elsevier Mosby, Missouri, USA. 2013; pp. 568-573.

Smith J. Canine prostatic disease: a review of anatomy, pathology, diagnosis and treatment. Theriogenology. $2008 ; 70: 375-83$

Vnuk D, Lipar M, Matičić D, Smolec O, Pećin M, Brkić A. Comparison of standard perineal herniorrhaphy and transposition of the internal obturator muscle for perineal hernia repair in the dog. Veterinarski arhiv. 2008; 78(3):197-207.

Watanabe K, Iwasakı R, Kondo S, Ohuchı T, Shıbata S, Saka1 H, Yamazoe K. A case of prostate B-cell lymphoma recognized in the contents of an irreducible perineal hernia in a dog. J Vet Med Sci. 2018; 80(5):784789

White, RA. Prostatic surgery in the dog. Clin Tech Small Anim Pract. 2000; 15(1):46-51. 